logical conditions ; but the noise-level at Singapore is not so intense as might be expected from its close proximity to one of the main thunderstorm areas of the world. Work on atmospheries from local storms is providing information on the power distribution with frequency in the lightning flash, and on the extent to which the wave-forms of the radiated disturbances can be explained in terms of the lightning mechanism.

The day-to-day variability in the electron densities of the various ionospheric layers is largely due to the corresponding variability in the wave and particle radiation from the Sun. The derivation of ionospheric indices of solar activity is of special importance for prediction purposes, and the report describes work which has been carried out on such indices for the $E$ and $F 2$ layers. As part of the International Geophysical Year Calendar Record, $E$-layer solar ionizing radiation indices, $\boldsymbol{F} 2$-disturbance indices and polar blackout indices have been calculated for each day of the International Geophysical Year. These daily indices should be invaluable for studies in other International Geophysical Year disciplines.

A rapidly increasing proportion of the activities of the Station at Slough is being devoted to various aspects of space research, and considerable observations have already been made on the direction of arrival of signals from satellites and on the received signal characteristics (Doppler shift, Faraday rotation, telemetry). The station also provides some 100 establishments and observers with predictions, at weekly intervals, of the times and directions of transit of satellites passing within radio-range of observers in the British Islos. Similar work is also being carried out at the Singapore sub-station.

In the radio-measurements and standards field the research and development have been concentrated mainly at frequencies greater than a few hundred megacycles per second. The Station has acted as the co-ordinating centre for the international comparison of milliwatt power-measuring techniques at centimetre wave-lengths, and satisfactory agreement has been found between measurements made with instruments of different types used in the standard laboratories of the United States, Japan and the United Kingdom. Recognition of the possible harmful biological effects of high-intensity electromagnetic radiation at frequencies greater than about $50 \mathrm{Mc} / \mathrm{s}$. has called for the development of reliably calibrated instruments to measure the flux density near highpower transmitters, and the report refers to work being carried out to meet this need.

The study of long-distance ionospheric transmission characteristics, using a sweep-frequency pulse technique, has continued and been extended to a $6,700-\mathrm{km}$. path between Ascension Island and Slough. It is found that during the daytime the modes of transmission are always very complex because of reflexions from tropical sporadic- $E$ ionization, and the sunset deterioration and fading of signals from stations in equatorial latitudes is associated with the break-up of this sporadic ionization at such times. Work on the lateral deviation of signals from Japanese short. wave stations shows that there are often periods when the signals depart significantly from the great-circle path and that propagation by way of auroral reflexion is probably a common feature of night-time propagation over these paths.

Tropospheric radio-wave work includes studies of scatter propagation, delay times on microwave links and the refractive properties of the lower atmosphere. Extensive signal-level, gain in height, fading and diversity measurements have been made over distances from 130 to $400 \mathrm{~km}$. ; but it would appear that no completely satisfactory explanation of troposphere scatter propagation is yet available. The bandwidths which can be used in short point-to-point microwave communication links are limited by multi-path propagation, and equipment is being developed at Slough to enable accurate detailed work on the signal-delay times to be measured. The refractive properties of the lower atmosphere are being investigated by means of airborne refractometer measurements, by radar sounding and also by using pressure, temperature and humidity data obtained from a balloon-borne wired-sonde.

Research at the Station on semiconductors has been mainly on transistors and their application. Microwave measurements on certain ferrite-aluminates in a resonant cavity and on transmission phenomena in wave-guides containing these materials has continued.

This 1959 report is of particular interest in that it is the last annual report of Dr. R. L. Smith-Rose, consequent on his retirement from the post in September $1960 . \quad$ W. J. G. BEYNoN

\title{
SAFEGUARDING HEALTH IN LONDON
}

$\mathrm{T}$ HE annual report on the work of the Scientific Branch, Public Health Department, London County Council, has been prepared by Dr. S. G. Burgers, scientific adviser to the Council*. The Department has 64 members of whom 34 are graduates, and the work covered by them during 1959 varied from routine analysis of foodstuffs - still very necessary - to investigating the properties of cleansing materials used in kitchens and laundries. Much research of a fundamental nature is carried out and opens up many possibilities for economic exploitation. The Council is to be commended for the high quality of the investigations carried out by this section of its staff.

* London County Council. Public Health Department-Scientific Branch. Annual Report of the Scientific Adviser for the year 1959. Pp. 46. (London: Iondon County Council, 1960.) 1s, 3d.
Particularly valuable research was connected with the treatment of sewage. How to produce sulphur from sulphate-enriched sludges was investigated by one team, and valuable information was obtained about the cost and practicability of the process, if conditions of national emergency should render its use necessary. Because of the long duration of these experiments, useful information was also accumulated about the effect of sulphide sludges on metal and other components of the experimental plant. Metals were found to be singularly free from corrosionstainless steel was as bright after three years exposure as it was initially, mild steel and cast iron (partly protected by calcium carbonate scale) were scarcely affected and steel bolts immersed for eighteen months could be unscrewed with ease. Brass and lead, 
except for a slight discoloration due to a sulphide film, were almost unaffected, but the zinc coating on the galvanized iron heating coils had completely disappeared, although this may have been due to electrolytes other than sulphides. Rubber was apparently unaffected.

Experiments were also continued on the final disposal of concentrated foam liquids, with particular reference to stripping by means of activated carbon. Aqueous solutions of 1,000 p.p.m. of sodium tetrapropylene benzene sulphonate were passed through a column of $1 \mathrm{in}$. diam. and $8 \mathrm{in}$. long, containing 100 gm. of activated carbon. The carbon was soaked in water before use, and care was taken to maintain the liquid level half an inch above the carbon column. During continuous flow the activated charcoal showed almost complete adsorption of the detergent present in the solution in the early part of the test; it was capable of extracting about 90 per cent of the detergent after it had adsorbed 27 per cent of its own weight of surface-active material and could still extract 50 per cent after adsorbing 38 per cent of its own weight. In a later experiment, a solution of 1,000 p.p.m. of sodium tetrapropylene benzene sulphonate in the final effiuent from an activated sludge plant was passed through a column containing $100 \mathrm{gm}$. of activated carbon. A gauze pad was used to intercept suspended solids before the liquid reached the activated carbon in order to avoid choking the interstices in the column. Although adsorption was good, there was evidence that the carbon failed more quickly than when aqueous solutions were used, probably because of adsorption of other constituents of the effluent.

As activated carbon is expensive, attention was given to the possibility of regenerating the material. Attempts to displace the surface-active materials with solvents had only a limited success, and acidification of the dried exhausted carbon, followed by extraction with trichlorethylene, resulted in the removal of only a small proportion of the synthetic detergent in the form of its sulphonic acid.

The most promising method of disposal of condensed foam liquids appeared to be by spraying the foam with surface-activated sludge and allowing the solid content of the material to settle. In the process, the detergent concentration of the supernatant liquor might be expected to be reduced from about $500-600$ to $30-40$ parts per million, which could easily be treated by admission to primary sedimentation tanks.

Continuing a long-term investigation into the incidence of air pollution, volumetric instruments again indicated a reduction of 7 per cent in the average concentration of smoke in the air of London during the year, and this progressive tendency for improvement has continued since the inception of the Clean Air Act at the beginning of 1957. The sulphur dioxide concentration, for the first time, showed a similar reduction. The improvement was mainly attributable to exceptionally good weather in December, in which the average smoke concentration was only half the usual figure. It is probable that mild weather at the end of the year resulted in reduced domestic coal consumption, and, if this is true, the improvement may not be permanent. It is of interest that during the unusually fine summer the degree of pollution, though naturally low, was very similar to that of the previous cold, wet summer.

A five-month investigation into conditions at Camden Depot was completed, showing that a house adjacent to the railway was subjected to concentrations of black smoke and sulphur dioxide which were on the average 102 and 43 per cent respectively higher than the general London-levels. With the wind in certain directions, the average concentrations rose to at least 200 and 100 per cent respectively above the same London-levels. The situation is expected to improve with the gradual replacement of steam by Diesel locomotives.

\section{RESEARCH IN THE SOCIAL SCIENCES}

$\mathrm{P}^{\mathrm{K}}$ IORITIES for research in the social sciences in industry have been indicated by A. B. Cherns, head of the Human Sciences Section, Department of Scientific and Industrial Research (Personnel Management, 42, No. 353 ; December 1960). In the field of ergonomics, for example, Cherns suggests that the man-machine relationship is a vital aspect of the study of man in industry. The social implications of the man-machine system are such as to justify more attention from social scientists perhaps as members of mixed ergonomic and sociological teams. Ergonomics is a field in which practical applications are easy to appreciate.

The development of adequate criteria of industrial relations should receive a high priority. Have the criteria also to develop indicators? Could the industrialist be advised what chart he should put on his wall to give him a guide to the industrial relations formulated in his plant? Until this be done, the claim to have extracted the full practical value from research cannot be substantiated. A wide comparative study would seem to be required.
The approach of Flanders and others, which aims at developing a study of industrial relations in all its aspects-economic, legal, psychological, sociological and historical-may woll provide the stimulation that is needed both to give point to and to encourage wide comparative studies.

Thero has been an uneasy tug-of-war between interpretations of workshop behaviour based on views of the man in the workshop as an economical and rational animal and those based on views of him as a nexus of social roles-the economic and the sociological points of view. More accurate and systematic observation is a high priority - but not of the extended, reporting type with platitudinous conclusions.

More analysis of the pressures on the individual in industry is required ; in particular, incentive payment systems, mothods and standards of inspection, the structure and organization of management, and delegation of responsibility.

The study of individual responses to pressures is as important as the study of the pressures themselves. 